\title{
Hybrid $\mathrm{Co}_{3} \mathrm{O}_{4} @ \mathrm{Co}_{9} \mathrm{~S}_{8}$ Electrocatalysts for Oxygen Evolution Reaction
}

\author{
Yong-Li Tong ${ }^{1,2}$, Lei Xing ${ }^{1}$, Mei-Zhen Dai ${ }^{1}$ and Xiang $W^{1 *}$ \\ ${ }^{1}$ School of Materials Science and Engineering, Shenyang University of Technology, Shenyang, China, ${ }^{2}$ School of Science, \\ Shenyang Ligong University, Shenyang, China
}

It is very essential to design an efficient and low-cost electrocatalyst for oxygen evolution reaction (OER). In this work, we report synthesis of $\mathrm{Co}_{3} \mathrm{O}_{4} @ \mathrm{Co}_{9} \mathrm{~S}_{8}$ heterostructures (Co-HSs) by employing $\mathrm{CO}_{3} \mathrm{O}_{4}$ nanowires (Co-NWs) as the precursor on nickel foam though a facile hydrothermal method. The unique structures can combine the advantages of one-dimensional nanowires and two-dimensional nanosheets, simultaneously, which possess plentiful defect atoms and active sites. The as-prepared Co-HSs exhibit excellent electrocatalytic performance for OER, which present a low overpotential of $80 \mathrm{mV}$ at $10 \mathrm{~mA} \mathrm{~cm}^{-2}$ during OER process and small Tafel slope of $107.2 \mathrm{mV} \mathrm{dec}^{-1}$.

Keywords: nanosheets, $\mathrm{Co}_{3} \mathrm{O}_{4} @ \mathrm{Co}_{9} \mathrm{~S}_{8}$, heterostructures, electrocatalysis, OER

\section{OPEN ACCESS}

Edited by:

Jiatao Zhang,

Beijing Institute of Technology, China

Reviewed by:

Zhouguang Lu,

Southern University of Science and

Technology, China

Dongxiang Li,

Qingdao University of Science and

Technology, China

*Correspondence:

Xiang Wu

wuxiang05@sut.edu.cn

Specialty section:

This article was submitted to

Colloidal Materials and Interfaces,

a section of the journal

Frontiers in Materials

Received: 11 June 2019 Accepted: 06 September 2019

Published: 01 October 2019

Citation:

Tong Y-L, Xing L, Dai M-Z and WU X (2019) Hybrid $\mathrm{Co}_{3} \mathrm{O}_{4} @ \mathrm{Cog}_{9} \mathrm{~S}_{8}$ Electrocatalysts for Oxygen Evolution

Reaction. Front. Mater. 6:233.

doi: 10.3389/fmats.2019.00233

\section{INTRODUCTION}

In general, overall water splitting can be divided into two half reactions, namely OER (Zhao et al., 2016; Xuan et al., 2019) and hydrogen evolution reaction (HER) (Deng et al., 2017). However, OER usually presents the disadvantage of high potential and low efficiency. To date, many attempts have been made to improve the electrocatalytic performance (Hu et al., 2018; Liu Y. et al., 2019). Of all electrocatalytic materials, $\mathrm{RuO}_{2}$ (Abbasi et al., 2016) and $\mathrm{IrO}_{2}$ (Lee et al., 2012) exhibit the best electrocatalytic activities, but their practical application is restricted to some extent because of their scarcity and high cost. Therefore, it is important to develop rich and low-cost alternatives.

Transition metal oxides have been extensively studied due to their excellent electrocatalytic properties, such as $\mathrm{MCo}_{2} \mathrm{O}_{4}$ (Zhao et al., 2019a), $\mathrm{NiFeO}_{\mathrm{x}}$ ( $\mathrm{Li}$ et al., 2019), $\mathrm{CoMoO}_{4}$ (Liu H. Q. et al., 2019), $\mathrm{NiCo}_{2} \mathrm{O}_{4}$ (Zhao et al., 2019b), $\mathrm{Co}_{3} \mathrm{O}_{4}$ (Tan et al., 2019). Among them, $\mathrm{Co}_{3} \mathrm{O}_{4}$ is a representative example owning to its earth-abundance, durability and high efficiency (Xu et al., 2016). In previous reports, Wang et al. constructed a large number of defect atoms using a plasma-engraved $\mathrm{Co}_{3} \mathrm{O}_{4}$ nanosheets method with high specific activity. Compared with a pristine sample, its activity is increased by 10 times. The overpotential of the as-obtained samples is $300 \mathrm{mV}$ at $10 \mathrm{~mA} \mathrm{~cm}$ (Zhao et al., 2016). Li et al. prepare ultrathin $\mathrm{Co}_{3} \mathrm{O}_{4}$ nanomeshes with many defect atoms and large surface area by an etching-free one-step method. The prepared sample exhibited the overpotential of $307 \mathrm{mV}$ at $10 \mathrm{~mA} \mathrm{~cm}^{-2}$ (Li et al., 2018a). Ma and coworkers fabricate $\mathrm{Co}_{3} \mathrm{O}_{4}$ nanocrystals grown on nitrogen-doped grapheme oxide with the overpotential of $380 \mathrm{mV}$ at $10 \mathrm{~mA} \mathrm{~cm}{ }^{-2}$ (Han et al., 2017). However, the catalytic performance of $\mathrm{Co}_{3} \mathrm{O}_{4}$ electrode materials is not satisfactory due to its poor conductivity. Moreover, the OER process is a four-step electron transfer one, which leads to kinetic sluggishness during the reaction process compared to HER with a two-step process. Therefore, many efforts have been made to improve its electrocatalytic efficiency, such as etching (Liu et al., 2017; Lu et al., 2017), doping (Chai et al., 2017; Wang et al., 2018), and facet control (Yang et al., 2017; Li et al., 2018b). Among them, etching is an effective method to increase oxygen defects, which 
make the as-obtained catalysts thin or porous. Therefore, heterostructures are considered to be an effective method because they combine the advantages of different materials.

In this work, we report ultrathin $\mathrm{Co}_{3} \mathrm{O}_{4} @ \mathrm{Co}_{9} \mathrm{~S}_{8}$ heterostructures (Co-HSs) as electrocatalysts by a simple etching $\mathrm{Co}_{3} \mathrm{O}_{4}$ nanowires (Co-NWs) approach, revealing a low overpotential of $80 \mathrm{mV}$ at $10 \mathrm{~mA} \mathrm{~cm}^{-2}$, low Tafel slope of $107.2 \mathrm{mV} \mathrm{dec}^{-1}$. The prepared samples show excellent cycle activity and still keep $100 \%$ current retention after $13 \mathrm{~h}$. The unique structure can provide many defect atoms and active sites. It speeds up electron transfer and then enhances electrocatalytic performance for OER.

\section{EXPERIMENTAL}

\section{Material Preparation}

All the chemicals were of analytical grade and used as purchased. Prior to typical synthesis, a piece of nickel foam $\left(4 \times 4 \mathrm{~cm}^{2}\right)$ was immersed in $0.5 \mathrm{M}$ hydrochloric acid for $0.5 \mathrm{~h}$, followed by ultrasonic rinsing repeatedly with distilled water and alcohol to remove grease, nickel oxide, and other impurities from surface. Next, the nickel foam was dried in an oven at $60^{\circ} \mathrm{C}$ for $10 \mathrm{~h}$. In a typical procedure, $1.443 \mathrm{~g} \mathrm{Co}\left(\mathrm{NO}_{3}\right)_{2}, 1.800 \mathrm{~g}$ urea and $0.900 \mathrm{~g}$ $\mathrm{NH}_{4} \mathrm{~F}$ were dissolved in $60 \mathrm{ml}$ deionized water, and then stirred for $30 \mathrm{~min}$ to obtain a pink clear solution. The solution and the pre-treated $\mathrm{Ni}$ foam were transferred to a $100 \mathrm{ml}$ autoclave heated to $120^{\circ} \mathrm{C}$ for $6 \mathrm{~h}$. After naturally cooling to room temperature, the as-obtained samples were washed repeatedly with deionized water and alcohol, respectively. Subsequently, the sample was dried at $60^{\circ} \mathrm{C}$ for $10 \mathrm{~h}$ in oven. Finally, the as-synthesized samples were annealed at $350^{\circ} \mathrm{C}$ for $2 \mathrm{~h}$.

The Co-HSs were synthesized by vulcanizing the prepared CoNWs. $0.40 \mathrm{~g} \mathrm{Na}_{2} \mathrm{~S}$ was dissolved into $40 \mathrm{ml}$ of deionized water and stirred until a clear solution appeared. Next, the abovementioned solution was put into a $100 \mathrm{ml}$ autoclave. Then the autoclave was maintained at $120^{\circ} \mathrm{C}$ for $6 \mathrm{~h}$. After cooling to room temperature, the as-obtained products were washed several times, and dried at $60^{\circ} \mathrm{C}$ overnight.

\section{Structure Characterization}

The morphology and structure of the as-prepared products were studied by scanning electron microscopy (SEM, Gemini 30071-31), X-ray diffraction analyzer (XRD, 7000, Shimadzu) by $\mathrm{Cu} \mathrm{K} \alpha$ radiation $(\lambda=1.5406 \AA)$ at $40 \mathrm{kV}$ and transmission electron microscopy (TEM, FEI Tecnai F20, 200kV). X-ray photoelectron spectroscopy (XPS) was used to investigate elemental composition of the sample surface by ESCALAB250 with an $\mathrm{Al} \mathrm{K \alpha}$ sources.

\section{Electrochemical Characterization}

The electrochemical properties of the as-synthesized products were conducted by using an electrochemical workstation (Shanghai Chenhua CHI660e) in a three-electrode system. The as-prepared sample is used as the work electrode, Pt plate as the auxiliary electrode and the saturated calomel electrode (SCE) as the reference electrode. All potentials were converted to reversible hydrogen electrode (RHE) potentials according to the
Nernst equation: $\mathrm{E}_{\mathrm{RHE}}=\mathrm{E}_{\mathrm{SCE}}+0.198+0.059 \times \mathrm{pH}$. $\mathrm{E}_{\mathrm{SCE}}$ is measured potential. The overpotential $(\eta)$ was calculated with the equation: $\eta=\mathrm{E}_{\mathrm{RHE}}-1.23$.

\section{RESULTS AND DISCUSSION}

XRD patterns were used to analyze the phase composition and crystal structure of the Co-NWs and Co-HSs samples. Figure 1A shows the characteristic diffraction peaks of the samples. The peak positions located at $44.6^{\circ}, 52.0^{\circ}, 76.6^{\circ}$ are the peaks of nickel foam (JCPDS NO. 42-0712). The other peaks at $31.3^{\circ}$, $36.9^{\circ}, 55.7^{\circ}, 59.4^{\circ}, 65.2^{\circ}$ are assigned to (220), (311), (422), (511), and (440) crystal planes of spinel $\mathrm{Co}_{3} \mathrm{O}_{4}$ samples (JCPDS NO. 42-1467). No other diffraction peaks were detected, suggesting their high purity. Figure 1B is XRD pattern of the sample after vulcanizing. In addition to the diffraction peaks from $\mathrm{Co}_{3} \mathrm{O}_{4}$ sample, the peaks at $29.7^{\circ}, 31.1^{\circ}, 39.4^{\circ}, 40.6^{\circ}, 61.7^{\circ}, 65.1^{\circ}$, and $76.4^{\circ}$ correspond to (311), (222), (331), (420), (622), (444), and (800) crystal planes of $\mathrm{Co}_{9} \mathrm{~S}_{8}$ (JCPDS No. 02-1459). It reveals that $\mathrm{Co}_{3} \mathrm{O}_{4}$ samples were vulcanized partially.

To further confirm the composition of the sample, XPS measurements are carried out. Figure 1C shows five elements $(\mathrm{Ni}, \mathrm{Co}, \mathrm{O}, \mathrm{C}$, and $\mathrm{S})$ in the full spectrum. The binding energies at $887.2,807.2,540.2$, and $172.1 \mathrm{eV}$ correspond to $\mathrm{Ni} 2 \mathrm{p}$, Co $2 \mathrm{p}, \mathrm{O} 1 \mathrm{~s}$, and $\mathrm{S} 2 \mathrm{p}$, respectively. Figure 1D shows Co $2 \mathrm{p}$ XPS spectra with two sharp $2 \mathrm{p}_{1 / 2}$ and $2 \mathrm{p}_{3 / 2}$ doublet peaks of $\mathrm{Co}^{2+}$ and $\mathrm{Co}^{3+}$ with separation of $16.4 \mathrm{eV}$ and a pair of shake-up satellites. The fitting peaks at 797.2 and $781.7 \mathrm{eV}$ correspond to $\mathrm{Co}^{2+}$, whereas the fitting peaks at 795.7 and $779.4 \mathrm{eV}$ are identified as $\mathrm{Co}^{3+}$. The O 1s XPS spectra (Figure 1E) are identified by four peaks at 529.5,531.2, 532.5, 533.5 eV, which correspond to the binding energy between oxygen atoms and basal plane, oxygen atoms binding to defect atoms, oxygen atoms in hydroxyl groups, and adsorbed water molecules, respectively. The $\mathrm{O}$ signal between oxygen atoms and defect atoms indicates the asprepared products possess many oxygen defect atoms (Zhuang et al., 2017). In addition, S 2p fitting spectra at 169.4 and $167.6 \mathrm{eV}$ can be ascribed to $S 2 p_{1 / 2}$ and $S 2 p_{3 / 2}$, respectively, as shown in Figure 1F. The results are consistent with XRD results.

The morphologies of the as-obtained products were observed by SEM first. Figure $\mathbf{2 a}$ shows that the many nanowires are uniformly covered on the surface of nickel foam. Further observation finds that the average diameter of each nanowire is tens of nanometers (Figure 2b). The shapes of the hybrid products present sheet-like structures after vulcanizing, as shown in Figures $\mathbf{2 c}$,d. The spatial structure can combine the advantages of one dimensional nanowires and two-dimensional nanosheets with large specific surface area and active sites. The low TEM image in Figure 2e further proves the sheet-like structure of the products. HRTEM image shows the lattice spacings between adjacent lattice fringes are 0.243 and $0.191 \mathrm{~nm}$, respectively, which correspond to (311) and (511) planes for $\mathrm{Co}_{3} \mathrm{O}_{4}$ and $\mathrm{Co}_{9} \mathrm{~S}_{8}$ material (Figure 2f).

Cyclic voltammetry $(\mathrm{CV})$ curve is an important indicator to investigate the electrochemical performance of the product in a traditional three-electrode system. From Figures $\mathbf{3 A}, \mathbf{B}$, it 

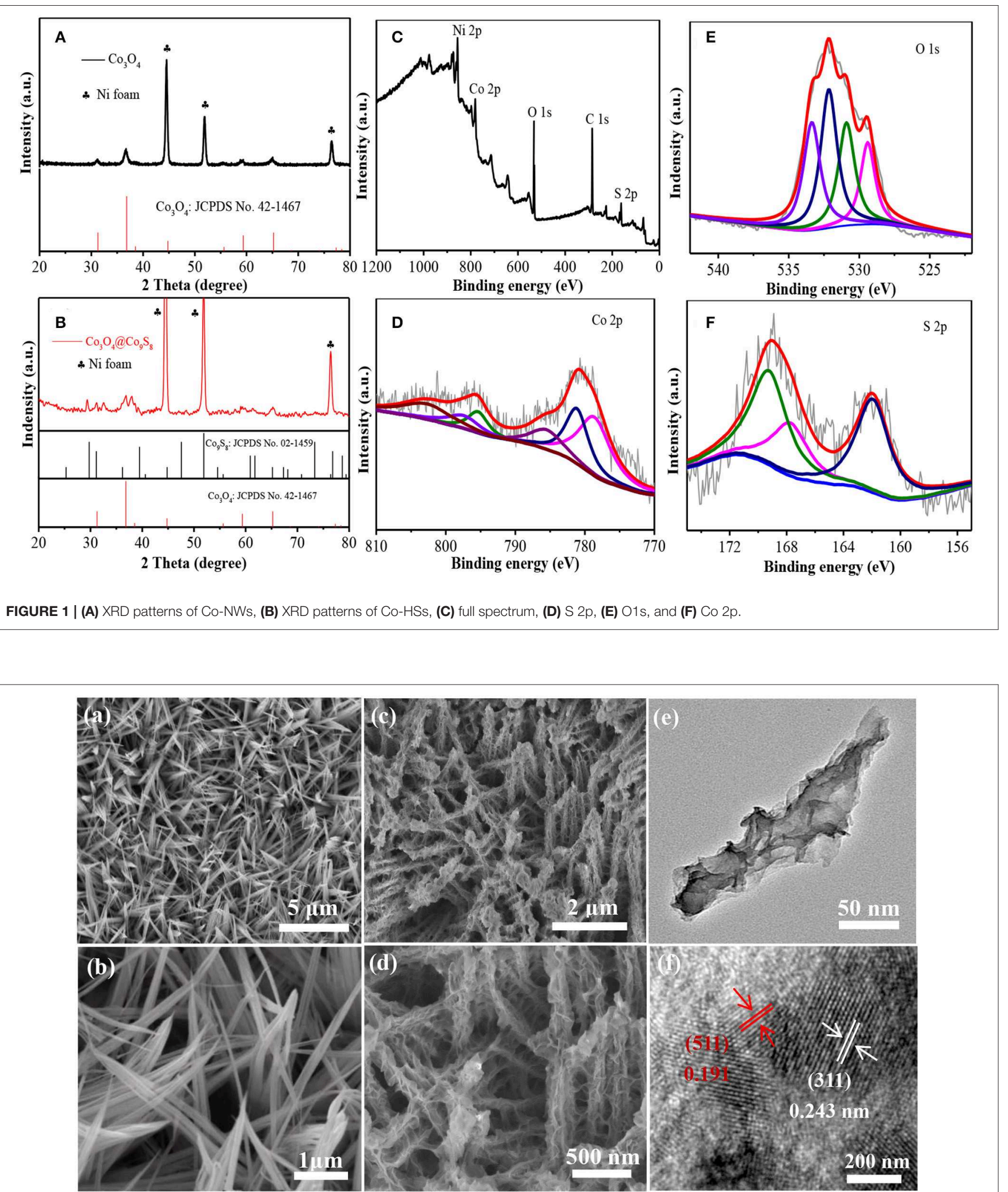

FIGURE 2 | Morphology characterization, $(\mathbf{a}, \mathbf{b})$ SEM image of Co-NWs, $(\mathbf{c}, \mathbf{d})$ Co-HSs, and $(\mathbf{e}, \mathbf{f})$ TEM images of the Co-HSs. 

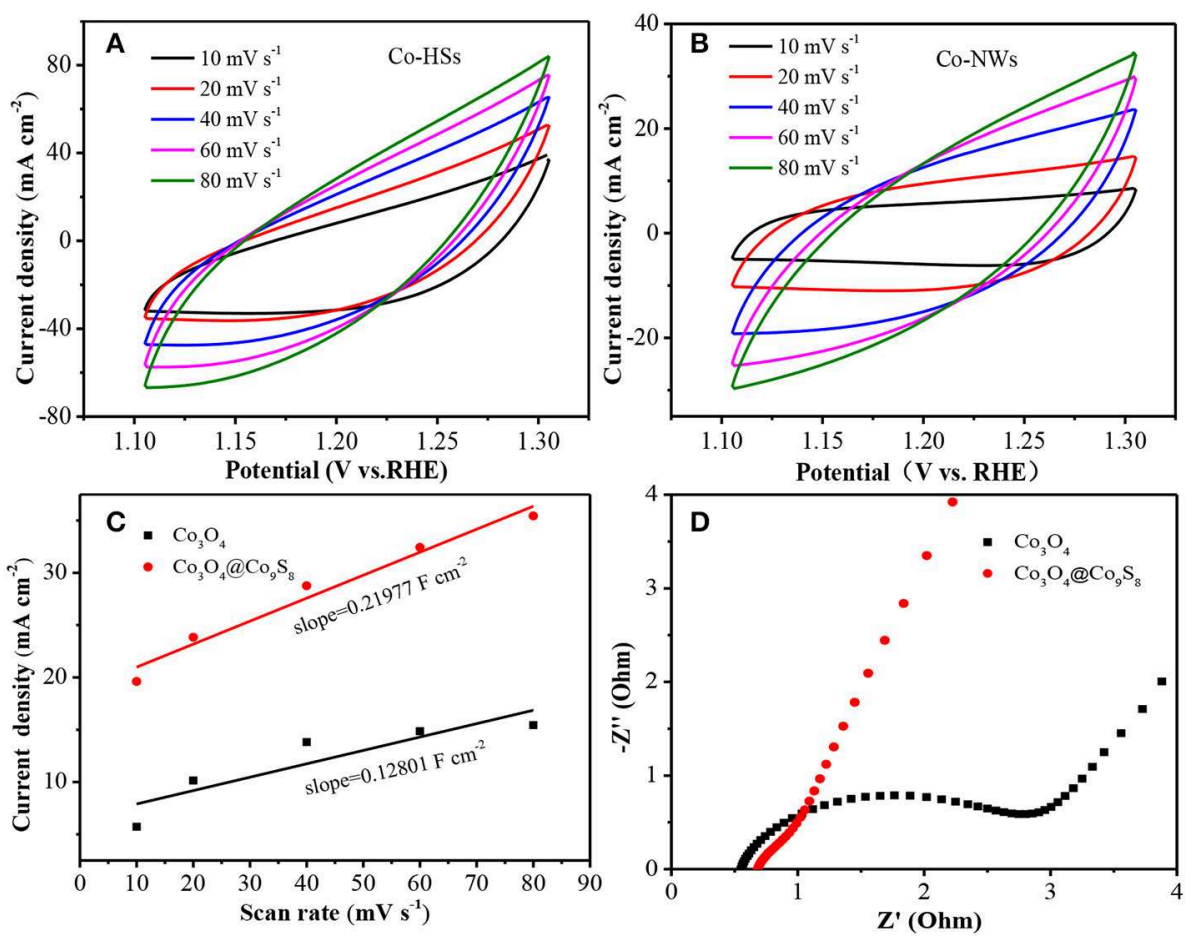

FIGURE 3 | Electrochemical measurements of Co-NWs and Co-HSs, (A) CV curves, (B) CV curves, (C) CV fitting curves, and (D) EIS measurements.

can be found that the shape of CV curves does not change with the increasing of scan rate. And the charging current of Co-HSs is larger than that of Co-NWs at the same scan rate, indicating that the prepared samples possess larger areas than Co-NWs. Then, the electrochemical double-layer capacitances $\left(C_{\mathrm{dl}}\right)$ of the electrodes are estimated by using the following equation: $i=v C_{\mathrm{dl}}$ ( $i$ is current density, $v$ refers to scan rate). Through the linear relationship between $i$ and $v$, the $C_{\mathrm{dl}}$ of CoHSs and Co-NWs are 0.2198 and $0.1280 \mathrm{~F} \mathrm{~cm}^{-2}$, respectively (Figure 3C). The electrochemically active surface area (ECSA) plays the crucial role in evaluating the ability of water oxidation of electrocatalyst. The as-prepared composite shows a high ECSA and many active sites, suggesting that the Co-HSs presents better electrocatalytic performance than that of Co-NWs. EIS is studied in a frequency range from 0.01 to $100,000 \mathrm{~Hz}$ with an amplitude of $5 \mathrm{mV}$ (Figure 3D). Charge transfer resistance $\left(R_{\mathrm{ct}}\right)$ can be obtained by the diameter of the semicircle at the high frequency region in Nyquist plots. The smaller the diameter, the faster the charge transfers. It can be found that the resistance of Co-HSs is much smaller than that of Co-NWs.

Then, the electrocatalytic activities of the samples are investigated further by linear sweep voltammetry (LSV) at $2 \mathrm{mV}$ $\mathrm{s}^{-1}$ for OER. Co-HSs show lower OER onset potential $(1.28 \mathrm{~V})$ than Co-NWs $(1.39 \mathrm{~V})$ (Figure 4A). After a run time of $13 \mathrm{~h}$, Co-HSs still show a low potential of $1.32 \mathrm{~V}$, indicating that the Co-NWs show excellent cycle stability. The overpotential is very important to evaluate oxygen evolution ability. Co-HSs require merely $80 \mathrm{mV}$ at $10 \mathrm{~mA} \mathrm{~cm}^{-2}$ to trigger OER, which is lower than Co-NWs. It shows that the synthesized samples are more prone to water splitting than Co-NWs at the same current density. At $100 \mathrm{~mA} \mathrm{~cm}^{-2}$, Co-HSs exhibit the overpotential of 350 and $380 \mathrm{mV}$ after cycling, respectively. However, the CoNWs require $420 \mathrm{mV}$ to achieve $100 \mathrm{~mA} \mathrm{~cm}{ }^{-2}$ (Figure 4B). It is the case that the interfaces of hybrid structures cause the redistribution of charge, which could cause the change of the Gibbs' free energy (Wang et al., 2017). The electronegativity of sulfur is stronger than that of oxygen, the charge can transfer from $\mathrm{Co}_{3} \mathrm{O}_{4}$ nanowires to $\mathrm{Co}_{9} \mathrm{~S}_{8}$ nanosheets until the $\Delta \mathrm{G}_{\mathrm{H}}$ tends thermo-neutral state (Wang et al., 2017). In alkaline environment, a four-step reaction for OER can be expressed by the following mechanisms:

$$
\begin{aligned}
& \mathrm{OH}^{-}+{ }^{*} \rightarrow \mathrm{OH}^{*}+\mathrm{e}^{-} \\
& \mathrm{OH}^{*}+\mathrm{OH}^{-} \rightarrow \mathrm{O}^{*}+\mathrm{H}_{2} \mathrm{O}+\mathrm{e}^{-} \\
& \mathrm{O}^{*}+\mathrm{OH}^{-} \rightarrow \mathrm{OOH}^{*}+\mathrm{e}^{-} \\
& \mathrm{OOH}^{*}+\mathrm{OH}^{-} \rightarrow \mathrm{O}_{2}+\mathrm{H}_{2} \mathrm{O}+\mathrm{e}^{-}
\end{aligned}
$$

Where * refers active site. The performance of the samples is mainly affected by the second process (14). The charge transfer reduces Fermi energy, which reduces the filling of antibonding states and increases $\mathrm{O}^{*}$ absorption. The overpotential in this work is lower than those of many other Co-based electrocatalysts (Table 1; Mendoza-Garcia et al., 2016; Yuan et al., 2016; Zhao et al., 2016; Chai et al., 2017; Han et al., 2017; Tahir et al., 2017; Yang et al., 2017; Li et al., 2018a,b; Liu et al., 2018; Wang et al., 2018).

Tafel slope is used to reflect the catalytic mechanism of OER, which bridges the relationship between overpotential and current 

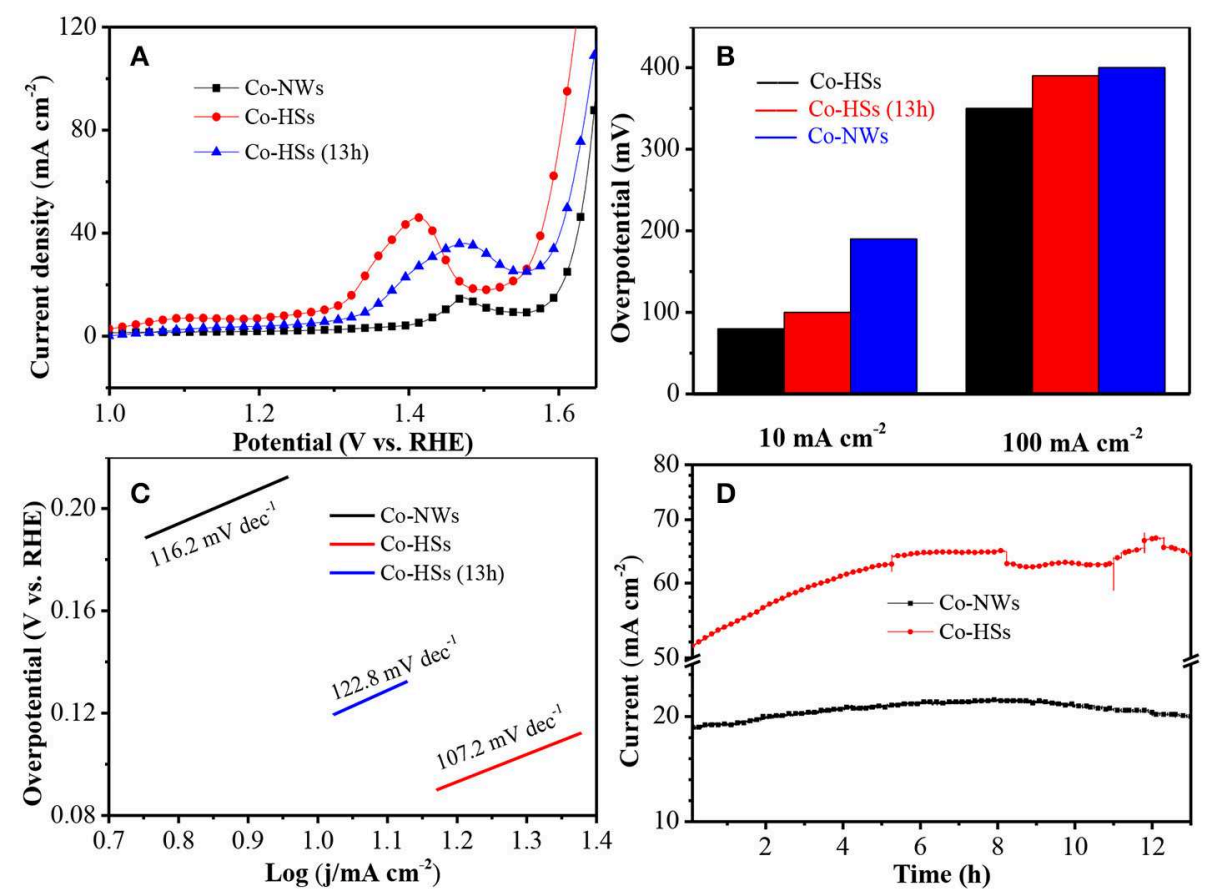

FIGURE 4 | Electrochemical measurements of Co-NWs, Co-HSs, and Co-HSs (after 13 h), (A) LSV curves, (B) Comparison of the overpotential at the current densities of 10 and $100 \mathrm{~mA} \mathrm{~cm}^{-2}$, (C) Tafel plot, and (D) long cycle stability.

TABLE 1 | Comparison of the as-prepared Co-HSs electrochemical performance with literature reported the Co-based electrocatalysts.

\begin{tabular}{|c|c|c|c|}
\hline Catalysts & Electrolyte & $\eta\left(10 \mathrm{~mA} \mathrm{~cm}^{-2}\right)$ & References \\
\hline Co-HSs & $1 \mathrm{M} \mathrm{KOH}$ & $80 \mathrm{mV}$ & This work \\
\hline $\mathrm{Co}_{3} \mathrm{O}_{4} @ \mathrm{MoS}_{2}$ & $1 \mathrm{M} \mathrm{KOH}$ & $90 \mathrm{mV}$ & Liu et al., 2018 \\
\hline $\mathrm{Co}_{3} \mathrm{O}_{4}$ Nanomeshes & $1 \mathrm{M} \mathrm{KOH}$ & $307 \mathrm{mV}$ & Li et al., 2018a \\
\hline Co hydroxide nanosheets & $1 \mathrm{M} \mathrm{KOH}$ & $326 \mathrm{mV}$ & Tahir et al., 2017 \\
\hline $\mathrm{Co}_{3} \mathrm{O}_{4}-\mathrm{NP} / \mathrm{N}-\mathrm{rGO}$ & $1 \mathrm{M} \mathrm{KOH}$ & $380 \mathrm{mV}$ & Li et al., 2018b \\
\hline $\mathrm{Co}_{3} \mathrm{O}_{4} @ \mathrm{~N}-\mathrm{rGO}$ Nanosheets & $1 \mathrm{M} \mathrm{KOH}$ & $490 \mathrm{mV}$ & Han et al., 2017 \\
\hline $\mathrm{P}-\mathrm{CO}_{3} \mathrm{O}_{4} / \mathrm{NF}$ nanowires & $1 \mathrm{M} \mathrm{KOH}$ & $260 \mathrm{mV}$ & Wang et al., 2018 \\
\hline Co-B nanosheet & $0.1 \mathrm{M} \mathrm{KOH}$ & $520 \mathrm{mV}$ & Yang et al., 2017 \\
\hline $\mathrm{Co}_{3} \mathrm{O}_{4}$ nanosheets & $0.1 \mathrm{M} \mathrm{KOH}$ & $300 \mathrm{mV}$ & Zhao et al., 2016 \\
\hline Co-Fe phosphide & $0.1 \mathrm{M} \mathrm{KOH}$ & $370 \mathrm{mV}$ & Mendoza-Garcia et al., 2016 \\
\hline CoO nanosheet/graphene & $0.1 \mathrm{M} \mathrm{KOH}$ & $330 \mathrm{mV}$ & Yuan et al., 2016 \\
\hline P, N Co-doped graphene & $0.1 \mathrm{M} \mathrm{KOH}$ & $320 \mathrm{mV}$ & Chai et al., 2017 \\
\hline
\end{tabular}

density. Low value indicates excellent kinetic characteristics. In Figure 4C, Co-HSs show lower Tafel slope $\left(107.2 \mathrm{mV} \mathrm{dec}^{-1)}\right.$ than Co-NWs $\left(116.2 \mathrm{mV} \mathrm{dec}^{-1}\right)$, revealing their fast kinetics transfer process. The slope of the as-synthesized samples still increases even after $13 \mathrm{~h}$, suggesting their excellent cycling performance.

Finally, the long term durability of Co-HSs is measured through chronoamperometry potential with a current density of $52 \mathrm{~mA} \mathrm{~cm}^{-2}$ (Figure 4D). As time increases, current intensity gradually increases. It reaches a maximum at $12 \mathrm{~h}$, and then begins to decrease. After $13 \mathrm{~h}$, current density for OER is $63 \mathrm{~mA}$ $\mathrm{cm}^{-2}$, indicating the increasing of $21 \%$. It may be attributed to the reason that gradual increasing of current intensity before $12 \mathrm{~h}$ induces slow wetting of the electrode material during the cycling process, which results in a gradual increasing of the reaction interface and the active site. Current intensity gradually decreases after $12 \mathrm{~h}$ due to the mechanical loss and activate sites during gas evolution process. Co-HSs show excellent cycle durability. It could be explained as follows. Firstly, active materials directly grown on the substrate can ensure good electron contact and mechanical adhesion with the conducting substrate. Secondly, the synergistic effect between $\mathrm{Co}_{3} \mathrm{O}_{4}$ nanaowires and $\mathrm{Co}_{9} \mathrm{~S}_{8}$ nanosheets is beneficial to speed up the dynamics process. 
Thirdly, the as-prepared Co-HSs show abundant active sites, which can provide adequate chemical reaction spaces occurring between the active materials and electrolyte. Therefore, the asprepared Co-HSs provide excellent durability and high oxygen evolution performance.

\section{CONCLUSION}

In summary, Co-HSs have been synthesized by employing CoNWs as precursor though a facile hydrothermal method. The as-obtained samples present many active sites and low charge transfer resistance. As a electrocatalyst for OER, Co-HSs show high electrocatalytic activity compared to Co-NWs. Meanwhile, the obtained Co-HSs exhibit low overpotential and outstanding cyclic performance, revealing that the Co-HSs might be a promising candidate in water splitting.

\section{REFERENCES}

Abbasi, H. M., Jafarzadeh, K., and Mirali, S. M. (2016). An investigation of the effect of $\mathrm{RuO}_{2}$ on the deactivation and corrosion mechanism of a Ti/IrOH $+\mathrm{Ta}_{2} \mathrm{O}_{5}$ coating in an OER application. J. Electroanal. Chem. 777, 67-74. doi: 10.1016/j.jelechem.2016.07.036

Chai, G. L., Qiu, K. P., Qiao, M., Titirici, M. M., Shang, C. X., and Guo, Z. X. (2017). Active sites engineering leads to exceptional ORR and OER bifunctionality in P, N Co-doped graphene frameworks. Energy Environ. Sci. 10, 1186-1195. doi: 10.1039/C6EE03446B

Deng, S., Zhong, Y., Zeng, Y., Wang, Y., Yao, Z., Yang, F., et al. (2017). Directional construction of vertical nitrogen-doped 1T-2H MoSe $/$ Graphene shell/core nanoflake arrays for efficient hydrogen evolution reaction. $A d v$. Mater. 29:1700748. doi: 10.1002/adma.201700748

Han, X., He, G., He, Y., Zhang, J., Zheng, X., Li, L., et al. (2017). Engineering catalytic active sites on cobalt oxide surface for enhanced oxygen electrocatalysis. Adv. Energy Mater. 8:1702222. doi: 10.1002/aenm.2017 02222

Hu, E. L., Feng, Y. F., Nai, J. W., Zhao, D., Hu, Y., and Lou, X. W. (2018). Construction of hierarchical Ni-Co-P hollow nanobricks with oriented nanosheets for efficient overall watersplitting. Energy Environ. Sci. 11, 872-880. doi: 10.1039/C8EE00076J

Lee, Y., Suntivich, J., May, K. J., Perry, E. E., and Shao-Yang, H. (2012). Synthesis and activities of rutile $\mathrm{IrO}_{2}$ and $\mathrm{RuO}_{2}$ nanoparticles for oxygen evolution in acid and alkaline solutions. J. Phys. Chem. Lett. 3, 399-404. doi: 10.1021/jz2016507

Li, J. Q., Zheng, L., Song, Q. Q., and Xu, X. T. (2019). $\mathrm{NiFeO}_{\mathrm{x}}$ nanosheets tight-coupled with $\mathrm{Bi}_{2} \mathrm{WO}_{6}$ nanosheets to improve the electrocatalyst for oxygen evolution reaction. Appl. Surf. Sci. 478, 969-980. doi: 10.1016/j.apsusc.2019.02.029

Li, Y., Li, F. M., Meng, X. Y., Li, S. N., Zeng, J. H., and Chen, Y. (2018b). Ultrathin $\mathrm{Co}_{3} \mathrm{O}_{4}$ nanomeshes for the oxygen evolution reaction. ACS Catalysis 3, 1913-1920. doi: 10.1021/acscatal.7b03949

Li, Y., Zhong, C., Liu, J., Zeng, X., Qu, S., Han, X., et al. (2018a). Atomically thin mesoporous $\mathrm{Co}_{3} \mathrm{O}_{4}$ layers strongly coupled with $\mathrm{N}-\mathrm{rGO}$ nanosheets as highperformance bifunctional catalysts for $1 \mathrm{D}$ knittable Zinc-air batteries. $A d v$. Mater. 30:1703657. doi: 10.1002/adma.201703657

Liu, H. Q., Zhao, D. P., Hu, P. F., Liu, Y., Wu, X., and Xia, H. (2019). Boosting energy storage and electrocatalytic performances by synergizing $\mathrm{CoMoO}_{4} @ \mathrm{MoZn}_{22}$ core-shell structures. Chem. Eng. J. 373, 485-492. doi: 10.1016/j.cej.2019.05.066

Liu, J., Wang, J. S., Zhang, B., Ruan, Y. Y., Wan, H. Z., Jia, X., et al. (2018). Mutually beneficial $\mathrm{Co}_{3} \mathrm{O}_{4} @ \mathrm{MoS}_{2}$ heterostructures as highly efficient bifunctional catalyst for electrochemical overall-water-splitting. J. Mater. Chem. 6, 2067-2072. doi: 10.1039/C7TA10048E

\section{DATA AVAILABILITY STATEMENT}

The datasets generated for this study are available on request to the corresponding author.

\section{AUTHOR CONTRIBUTIONS}

Y-LT makes substantial contributions to conception and design. LX and M-ZD make contributions to acquisition of data. XW makes contributions to analysis and interpretation of data.

\section{FUNDING}

This project was supported by State Key Laboratory of New Ceramic and Fine Processing Tsinghua University (Grant No. KF201807).

Liu, Y., Dong, P., Li, M., Wu, H., Zhang, C., Han, L., et al. (2019). Cobalt nanoparticles encapsulated in nitrogen-doped carbon nanotube as bifunctional-catalyst for rechargeable Zn-air batteries. Front. Mater. 6:85. doi: 10.3389/fmats.2019.00085

Liu, Z., Zhao, Z., Wang, Y., Dou, S., Yan, D., Liu, D., et al. (2017). In situ exfoliated, edge-rich, oxygen-functionalized graphene from carbon fibers for oxygen electrocatalysis. Adv. Mater. 29:1606207. doi: 10.1002/adma.201606207

Lu, Z., Chen, G., Li, Y., Wang, H., Xie, J., Liao, L., et al. (2017). Identifying the active surfaces of electrochemically tuned $\mathrm{LiCoO}_{2}$ for oxygen evolution reaction. J. Am. Chem. Soc. 139, 6270-6276. doi: 10.1021/jacs.7b02622

Mendoza-Garcia, A., Su, D., and Sun, S. (2016). Sea urchin-like cobalt-iron phosphide as an active catalyst for oxygen evolution reaction. S. Nanoscale 8, 3244-3247. doi: 10.1039/C5NR08763E

Tahir, M., Pan, L., Idrees, F., Zhang, X., Wang, L., Zou, J. J., et al. (2017). Electrocatalytic oxygen evolution reaction for energy conversion and storage: a comprehensive review. Nano Energy. 37, 136-157. doi: 10.1016/j.nanoen.2017.05.022

Tan, P., Wu, Z., Chen, B., Xu, H., Cai, W., and Ni, M. (2019). Exploring oxygen electrocatalytic activity and pseudocapacitive behavior of $\mathrm{Co}_{3} \mathrm{O}_{4}$ nanoplates in alkaline solutions. Electrochim. Acta 310, 86-95. doi: 10.1016/j.electacta.2019.04.126

Wang, J., Liu, J., Zhang, B., Ji, X., Xu, K., Chen, C., et al. (2017). The mechanism of hydrogen adsorption on transition metal dichalcogenides as hydrogen evolution reaction catalyst. Phys. Chem. Chem. Phys. 19, 10125-10132. doi: 10.1039/C7CP00636E

Wang, Z. C., Liu, H. L., Ge, R. X., Ren, X., Ren, J., Yang, D. J., et al. (2018). Phosphorus-doped $\mathrm{Co}_{3} \mathrm{O}_{4}$ nanowire array: a highly efficient bifunctional electrocatalyst for overall water splitting. ACS Catal. 8, 2236-2241. doi: 10.1021/acscatal.7b03594

Xu, L., Jiang, Q. Q., Xiao, Z. H., Li, X. Y., Hou, J., Wang, S. Y., et al. (2016). Plasmaengraved $\mathrm{Co}_{3} \mathrm{O}_{4}$ nanosheets with oxygen vacancies and high surface area for the oxygen evolution reaction. Angew. Chem. Int. Ed. 55, 5277-5281. doi: 10.1002/anie.201600687

Xuan, L. L., Liu, X. J., and Wang, X. (2019). Cobalt phosphate nanoparticles embedded nitrogen and phosphorus-Co doped graphene aerogels as effective electrocatalysts for oxygen reduction. Front. Mater. 6:22. doi: 10.3389/fmats.2019.00022

Yang, L. B., Liu, D. N., Hao, S., Kong, R. M., Asiri, A. M., Zhang, C. X., et al. (2017). A cobalt-borate nanosheet array: an efficient and durable non-noblemetal electrocatalyst for water oxidation at near neutral pH. J. Mater. Chem. A 5, 7305-7308. doi: 10.1039/C7TA00982H

Yuan, W. Y., Zhao, M., Yuan, J., and Li, C. M. (2016). Ni foam supported three-dimensional vertically aligned and networked layered CoO nanosheet/graphene hybrid array as a high-performance oxygen evolution electrode. J. Power Sources 319, 159-167. doi: 10.1016/j.jpowsour.2016.04.044 
Zhao, D. P., Dai, M. Z., Liu, H. Q., Xiao, L., Wu, X., and Xia, H. (2019a). Constructing high performance hybrid battery and electrocatalyst by heterostructured $\mathrm{NiCo}_{2} \mathrm{O}_{4} @ \mathrm{NiWS}$ nanosheets. Cryst. Growth Des. 19, 1921-1929. doi: 10.1021/acs.cgd. 8 b01904

Zhao, D. P., Liu, H. Q., and Wu, X. (2019b). Bi-interface induced multi-active $\mathrm{MCo}_{2} \mathrm{O}_{4} @ \mathrm{MCo}_{2} \mathrm{~S}_{4} @ \mathrm{PPy} \quad(\mathrm{M}=\mathrm{Ni}, \mathrm{Zn})$ sandwich structure for energy storage and electrocatalysis. Nano Energy 57, 363-370. doi: 10.1016/j.nanoen.2018.12.066

Zhao, Y. F., Huang, S. F., Xia, M. R., Rehman, S., Mu, S. C., Kou, Z. K., et al. (2016). N-P-O co-doped high performance 3D graphene prepared through red phosphorous-assisted "cutting-thin" technique: a universal synthesis and multifunctional applications. Nano Energy 28, 346-355. doi: 10.1016/j.nanoen.2016.08.053
Zhuang, L., Ge, L., Yang, Y., Li, M., Jia, Y., Yao, X., et al. (2017). Ultrathin iron-cobalt oxide nanosheets with abundant oxygen vacancies for the oxygen evolution reaction. Adv. Mater. 29:1606793. doi: 10.1002/adma.201606793

Conflict of Interest: The authors declare that the research was conducted in the absence of any commercial or financial relationships that could be construed as a potential conflict of interest.

Copyright (C) 2019 Tong, Xing, Dai and Wu. This is an open-access article distributed under the terms of the Creative Commons Attribution License (CC BY). The use, distribution or reproduction in other forums is permitted, provided the original author(s) and the copyright owner(s) are credited and that the original publication in this journal is cited, in accordance with accepted academic practice. No use, distribution or reproduction is permitted which does not comply with these terms. 